\title{
Aspirin desensitization for urgent endovascular treatment of the aneurysm
}

\author{
Rita Aguiar*, Natália P Fernandes, Ana Mendes, Elisa Pedro, Manuel Pereira-Barbosa \\ From 6th Drug Hypersensitivity Meeting (DHM 6) \\ Bern, Switzerland. 9-12 April 2014
}

Hypersensitivity reactions to aspirin (acetylsalicylic acidASA) and other nonsteroidal anti-inflammatory drugs (NSAIDs) constitute only a subset of all adverse reactions to these drugs, but due to their severity they pose a significant risk to patients. The authors report a case of a 48 year old woman with asthma, hypertension, obstructive sleep apnea and a NSAIDs-exacerbated respiratory disease: hypersensitivity reactions induced by aspirin and metamizol manifesting primarily as bronchial obstruction and dyspnea. She was regulary medicated with budesonide 400mg 2x/day, ipratropium bromide dry powder inhaler once a day, montelukast $10 \mathrm{mg}$ /day, bilastine $20 \mathrm{mg}$ /day and terbutaline. The patient had a giant fusiform aneurysm with carotid-cavernous sinus partially thrombosed in a subacute phase. For endovascular treatment of aneurysm, the patient need a stent placement in the left internal carotid artery under antiplatelet therapy with ASA. The patient was referred to our Department and was submitted to a desensitization protocol in an emergence context due to the risk of aneurism rupture. At the time, her asthma was not controlled so it was necessary to carry out medication with bronchodilators and oral corticosteroids while doing the procedure. The protocol followed this sequence: on the first day $5,10,25,50,75,100$ and $250 \mathrm{mg}$ of ASA were administered at intervals of 30 minutes. On the second day the patient performed one single dose of $500 \mathrm{mg}$, without reactions. After surgery, she remained on $100 \mathrm{mg}$ of ASA daily without reaction. The authors sought to adapt a safe and practical protocol to allow the administration of ASA to patients with a NSAIDs-exacerbated respiratory disease. In live-saving situations is very important to reflect, reevaluate the indications and contraindications for desensitization. Note that it is possible to make a successful desensitization even in a patient with uncontrolled asthma.

Hospital Santa Maria, CHLN, Immunoallergology Department, Portugal
Published: 18 July 2014

doi:10.1186/2045-7022-4-S3-P25

Cite this article as: Aguiar et al.: Aspirin desensitization for urgent endovascular treatment of the aneurysm. Clinical and Translational Allergy 2014 4(Suppl 3):P25.

Submit your next manuscript to BioMed Central and take full advantage of:

- Convenient online submission

- Thorough peer review

- No space constraints or color figure charges

- Immediate publication on acceptance

- Inclusion in PubMed, CAS, Scopus and Google Scholar

- Research which is freely available for redistribution 